\title{
Empregadas domésticas e cuidadoras profissionais: compartilhando as fronteiras da precariedade ${ }^{\star}$
}

\author{
Graciele Pereira Guedes ** \\ Elisa Monçores ${ }^{\star \star *}$
}

Há considerável fluidez na fronteira entre a atuação das empregadas domésticas e as atribuições exercidas pelas cuidadoras profissionais. Mas o quão distintas são estas categorias ocupacionais em relação ao seu perfil socioeconômico? Ao longo deste artigo, com base nos dados da Pesquisa Nacional por Amostra de Domicílios (PNAD), buscamos responder se, durante o período 2002-2015, esses dois grupos apresentaram maiores aproximações ou inflexões em suas características. A partir de cinco dimensões analíticas - características individuais, condições de trabalho, grau de proteção trabalhista e social, situação domiciliar e isolamento/pertencimento -, as estatísticas apresentadas neste trabalho sugerem uma aproximação ao longo dos anos entre o perfil das trabalhadoras domésticas e o das profissionais de cuidado. Essa afirmação é válida para praticamente todos os indicadores analisados. Ambas as ocupações são marcadas pela precariedade no trabalho: combinam baixo nível de remuneração e de proteção social com alta carga horária de trabalho remunerado, somada a extensas jornadas não remuneradas. Ademais, ambas atividades são majoritariamente exercidas por mulheres pretas e pardas. Singularmente, a escolaridade é a única característica socioeconômica que de fato diferencia os dois grupos, consideravelmente mais alta para as cuidadoras.

Palavras-chave: Emprego doméstico. Cuidado. Cuidadoras. Mercado de trabalho.

\footnotetext{
* As autoras agradecem os comentários das coordenadoras e participantes do GT 13 - Dinâmicas Demográficas e Trabalho do XV Encontro Nacional da Abet, seminário no qual versão preliminar deste trabalho foi apresentada, bem como as sugestões e comentários de dois/duas pareceristas anônimos(as) da Rebep.

** Faculdade de Economia da Universidade Federal Fluminense (UFF), Niterói-RJ, Brasil (gracielepguedes@yahoo.com.br; https://orcid.org/0000-0001-5197-1294).

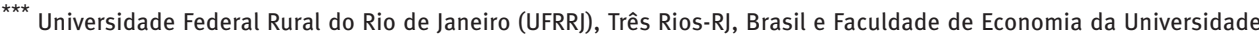
Federal Fluminense (UFF), Niterói-RJ, Brasil (elisa_moncores@hotmail.com; https://orcid.org/0000-0003-3070-9494).
} 


\section{Introdução}

0 trabalho de cuidado remunerado é exercido majoritariamente por mulheres, em uma extensão da situação verificada com o cuidado não remunerado. Esta característica reflete a perpetuação de um elo entre a divisão sexual do trabalho na esfera privada e a posição das mulheres na esfera pública. Ou seja, mesmo quando saem para o mercado de trabalho, há uma manutenção da divisão sexual do trabalho tradicional que faz com que as mulheres continuem sendo as principais responsáveis pelos cuidados, ainda que no âmbito mercantil.

No Brasil, uma massa não desprezível de trabalhadoras atua como pilar da prática de terceirização das atividades domésticas: em 2015, a partir da Pesquisa Nacional por Amostra de Domicílios (PNAD), elas formavam aproximadamente 5,0 milhões de empregadas domésticas e 1,3 milhão de cuidadoras profissionais.

As fronteiras que separam o trabalho exercido pelas cuidadoras profissionais e as empregadas domésticas são consideravelmente fluidas, sendo delicada a distinção entre as diferenças na atuação de um ou outro grupo (GUIMARÃES; HIRATA, 2016; GUIMARÃES; HIRATA; SUGITA, 2012). Em parte, o obscuro limite entre o trabalho de cuidadoras e o de empregadas domésticas é fruto da conhecida "polivalência" das atividades de cuidado. Esta afirmação pode ser observada no tratamento dado à ocupação de trabalhador doméstico nas PNADs. Embora seja possível separar a ocupação propriamente de cuidador (babás e cuidadores de jovens e adultos) das demais caracterizadas como serviços domésticos, a ocupação de trabalhador nos serviços domésticos engloba ainda uma miríade de funções. Dentre estas, incluem-se as de arrumadeira e arrumador, auxiliar de serviços, camareiro(a), carregador(a) de água, criado(a), curumim, caseiro(a), jardineiro(a), diarista, faxineiro(a), secretário(a) no serviço doméstico, lavador e lavadeira, passador e passadeira, servente, limpador(a) e a de empregado(a) doméstico(a).

Conforme destacam Guimarães e Hirata (2016), cuidar de uma pessoa exige, concomitantemente a um investimento afetivo e emocional, a realização de tarefas domésticas envolvidas no cuidado, como preparar a comida da qual ela se nutre, passar e lavar sua roupa e manter o ambiente limpo. As autoras acrescentam que as longas jornadas de trabalho das cuidadoras brasileiras tornam ainda mais difícil distinguir as tarefas das trabalhadoras domésticas e das cuidadoras. Ao contrário do que acontece em outros países, como na França ou no Japão, ${ }^{1}$ onde as cuidadoras possuem jornadas de apenas uma ou duas horas e visitam vários domicílios ao dia, as cuidadoras brasileiras estabelecem vínculos de trabalho semelhantes àqueles das empregadas domésticas, com longas jornadas diárias em um mesmo domicílio, o que torna mais difícil demarcar a diferença de seu trabalho para o da empregada doméstica. Além disso, poucas famílias brasileiras

\footnotetext{
${ }_{1}^{1}$ Para uma análise comparativa entre o trabalho de cuidado no Brasil, França e Japão, ver Guimarães, Hirata e Sugita (2012).
} 
possuem condições financeiras para contratar uma variedade de profissionais, acabando por contratar os serviços de apenas uma que, por sua vez, desempenha diversas funções.

A dita fluidez entre as categorias ganha ainda mais evidência quando se verifica que nem mesmo as próprias trabalhadoras dos cuidados costumam se reconhecer como tal. Em levantamento feito a partir dos dados da Pesquisa Emprego e Desemprego (PED), realizada em 2008 na Região Metropolitana de São Paulo, ${ }^{2}$ Guimarães, Hirata e Sugita (2012) verificaram que a maior parte das trabalhadoras que exerciam atividades de cuidado - que as enquadravam potencialmente como cuidadoras - se autoidentificavam como empregadas domésticas.

Frequentemente, a diferença mais relevante entre a denominação de cuidadora e a de empregada doméstica acontece no âmbito do status social que ambas as designações implicam. A princípio, assume-se que haveria uma maior valorização do exercício do trabalho das cuidadoras em face daquele desenvolvido pelas trabalhadoras domésticas, tendo em vista a precariedade e a invisibilidade econômica e social às quais tal ocupação foi historicamente submetida.

Embora a própria definição do termo cuidadora e das práticas a ele associadas careça de sentido próprio, a diferenciação do grupo das cuidadoras com relação ao das domésticas parece se estabelecer, até o momento, pela negação - “cuidadoras não são empregadas domésticas”. Por exemplo, é usual em empresas de intermediação de cuidadores a tentativa de aproximação da figura do cuidador daquela do microempreendedor individual, em paralelo ao afastamento da figura da empregada doméstica.

Ademais, apenas recentemente a profissão de cuidadora passou a contar com regulamentação própria, por meio do Projeto de Lei da Câmara (PLC) 11/16, aprovado pelo Senado em 21 de maio de $2019 .{ }^{3}$ Até então, a profissão seguia confundindo-se inclusive em termos legais ao emprego doméstico.

No caso da ocupação de empregada doméstica, esta obteve sua primeira regulamentação em 11 de dezembro de 1972, pela Lei n. 5.859, quase 30 anos após a Consolidação das Leis do Trabalho (CLT), de 1943, que excluía estas trabalhadoras da regulamentação dos direitos trabalhistas. A Constituição Federal de 1988 (CF/1988) expandiu mais alguns direitos às trabalhadoras domésticas e garantiu, por exemplo, a integração destas à previdência social (FRAGA, 2013). Mas a categoria apenas obteria sua equiparação aos trabalhadores regidos pela CLT a partir da Emenda Constitucional (EC) n. 72, de 2 de abril de 2013, posteriormente sancionada como Lei Complementar em 2 de junho de 2015 (LC n. 150/2015).

A EC n. 72, conhecida como a "PEC das domésticas", assegurou direitos antes não reconhecidos às empregadas domésticas, como a garantia de recebimento do salário

\footnotetext{
$\overline{2}$ A pesquisa foi realizada pela Fundação Seade, que colocou a base de dados à disposição das pesquisadoras.

${ }^{3}$ Em 08 de julho de 2019, o PLC aprovado pela Câmara foi vetado integralmente pela Presidência da República, sob alegação de inconstitucionalidade da restrição do livre exercício profissional (BRASIL, 2019). Até o momento da produção deste artigo, os vetos aguardavam apreciação do Congresso Nacional, que poderia acatá-los ou rejeitá-los.
} 
mínimo, décimo terceiro salário, duração do trabalho normal não superior a oito horas diárias e 44 horas semanais e repouso semanal remunerado.

Na prática, os efeitos da PEC estendiam-se às cuidadoras domiciliares, pois a lei considera empregados domésticos todos aqueles que prestam serviços contínuos e não lucrativos diretamente à pessoa ou à família em ambiente residencial. Inclusive o PLC 11/2016 prevê que, quando contratado por pessoa física para atuar em domicílio ou acompanhando as atividades da pessoa de quem cuida por mais de dois dias na semana, o cuidador será regido pela LC n. 150 de 2015, a mesma que regula as atividades das empregas domésticas. Logo, ainda que agora as cuidadoras possuam legislação específica, as próprias leis que regulamentam as profissões explicitam a dificuldade de dissociá-las por completo.

Importante ressaltar que, de acordo com a lei, os cuidadores podem trabalhar organizados sob três regimes: domiciliar (regido pela Lei do emprego doméstico), como microempreendedor individual (MEI), ou como CLT, quando contratado por pessoa jurídica. É provável que esta última opção se aplique em especial às profissionais atuantes em instituições de cuidado, isto é, fora do âmbito doméstico.

Outra diferença relevante em relação à legislação dos trabalhadores domésticos diz respeito à exigência de uma escolaridade mínima para o exercício da profissão, que é inexistente no caso das domésticas. Para as cuidadoras, a lei estabelece a necessidade de conclusão ao menos do ensino fundamental e a realização de um curso de qualificação profissional. A exigência de uma qualificação formal mínima para as cuidadoras, em oposição à ausência desta para as trabalhadoras domésticas, pode ser considerada um reforço à ideia de que as cuidadoras poderiam se diferenciar das domésticas pelo status da profissão, uma vez que o requisito da escolaridade pode funcionar como uma espécie de barreira à entrada na ocupação, tornando-a mais restritiva.

Ao contrário do emprego doméstico, o uso do termo "cuidadora” é relativamente recente no cotidiano brasileiro, mostrando-se presente apenas a partir dos anos 2000 (GUIMARÃES; HIRATA, 2016). Assim, pode-se pensar que essa nova possibilidade de nomeação - a cuidadora -, que carrega consigo um afastamento do status do emprego doméstico, mas ao mesmo tempo mantém ao menos em parte suas funções, seja capaz de promover a migração ocupacional de um contingente de mulheres outrora potencialmente empregadas no emprego doméstico. Neste artigo, são consideradas cuidadoras as mulheres que declararam exercer atividades de cuidados de crianças, jovens, adultos e idosos.

Esta conjectura não significa dizer que as mulheres já empregadas como trabalhadoras domésticas realizarão a migração para a função de cuidadoras - embora seja possível imaginar uma situação em que isso venha a acontecer em alguns casos. Apenas significa admitir a possibilidade de que uma nova ocupação possa estar absorvendo uma parcela da mão de obra feminina, cujo perfil potencialmente se assemelharia ao das empregadas domésticas.

Este artigo se propõe a examinar em que medida os perfis socioeconômicos dos dois grupos de trabalhadoras se distanciaram ou se aproximaram ao longo dos anos estudados. 
No interior deles distinguimos quatro subgrupos: empregadas domésticas diaristas; cuidadoras diaristas; cuidadoras domiciliares; e cuidadoras institucionais. 0 objetivo é realizar uma comparação da trajetória de indicadores quantitativos selecionados das empregadas domésticas brasileiras com aqueles encontrados para as cuidadoras profissionais, pontuando continuidades e inflexões. Tal comparação será realizada a partir dos dados das PNADs de 2002 a 2015, sendo que os indicadores analisados giram em torno de cinco dimensões: características individuais; condições de trabalho; grau de proteção trabalhista e social; situação domiciliar; e isolamento/pertencimento.

A análise aqui realizada privilegiou tanto o estudo das características individuais e de mercado de trabalho - como cor ou raça, idade e remuneração -, quanto fatores relacionados à situação intradomiciliar dessas mulheres, tais como posição no domicílio e o número de horas dedicadas às atividades domésticas. Busca-se, assim, estabelecer o diálogo entre as características observadas no mercado de trabalho e a configuração da esfera privada, a partir do entendimento de que os resultados vivenciados pelas mulheres na esfera pública são em parte condicionados por suas experiências na esfera privada.

Ademais, o estudo evolutivo comparado dessas ocupações no tempo abre espaço para um outro nível de investigação, que estuda o alinhamento do movimento observado no trabalho feminino às dinâmicas de mercado de trabalho e do próprio ciclo econômico. Assim, ao longo do trabalho, realizou-se um esforço de formular hipóteses a respeito da possível influência das modificações do quadro do mercado de trabalho brasileiro nos anos analisados sobre as ocupações em questão.

A seguir, é descrita a estratégia empírica utilizada no artigo. Posteriormente analisam-se os resultados encontrados para os dois grupos ocupacionais de interesse. Podemos adiantar que os resultados sugerem uma aproximação entre o perfil dos dois principais grupos, com algumas nuances, sobretudo no que se refere ao indicador de escolaridade. Por fim são apresentadas as considerações finais.

\section{Estratégia empírica}

Com o objetivo de responder às questões levantadas na introdução, analisamos indicadores selecionados no período que se estende de 2002 a 2015. A investigação tem como base a Pesquisa Nacional por Amostra de Domicílios (PNAD), realizada pelo Instituto Brasileiro de Geografia e Estatística (IBGE). Cabe ressaltar que não são apresentados dados para 2010, uma vez que em anos de Censo a PNAD não vai a campo.

Com vistas a compatibilizar a série de dados ao longo deste período, foram excluídas da amostra as observações pertencentes ao Norte Rural, que passaram a compor a pesquisa apenas em 2004. Ainda com objetivos de compatibilização, incluímos somente os ocupados de 15 anos ou mais de idade, tendo em vista que a consideração da idade ativa se alterou na PNAD ao longo do período de análise. A partir de 2011 passou-se a contemplar o limite mínimo de 15 anos, em substituição ao limiar de dez anos. 
Em termos de definição dos dois grupos de análise, por cuidador compreendemos os indivíduos classificados sob o código 5162 da Classificação Brasileira de Ocupações (CBO) do IBGE, que envolve tanto as atividades exclusivamente de cuidados de crianças quanto aquelas dedicadas a jovens, adultos e idosos, tais como babá, cuidador de idosos (domiciliar e institucional), mãe social e cuidador em saúde. Neste grupo, distinguimos dois subgrupos, o dos cuidadores domiciliares e o dos cuidadores institucionais.

Salienta-se que a divisão por ocupações nas PNADs não possui códigos específicos para cada um desses subgrupos, ou para as funções acima nomeadas: babá, cuidador de jovens, adultos e idosos (domiciliar e institucional), mãe social e cuidador em saúde. Contudo, para efeitos deste trabalho, consideramos cuidadores domiciliares todos os ocupados nos serviços domésticos com carteira, sem carteira e sem declaração de carteira, cujo código na CBO correspondia ao de cuidador (5162). Os cuidadores institucionais são, por sua vez, entendidos como aqueles classificados sob o código 5162, mas que não se enquadravam no critério de cuidador domiciliar. Por sua vez, por empregado doméstico ${ }^{4}$ entendemos os indivíduos classificados sob o código 5121 da CBO.

No interior dos dois grandes grupos analisamos o subgrupo das diaristas. Embora não conste no questionário das PNADs uma pergunta específica que demande aos indivíduos pertencentes a ambas as ocupações se são diaristas ou mensalistas, é possível identificar as trabalhadoras diaristas por meio de uma proxy. A aproximação utilizada consiste naquela apresentada por Costa, Barbosa e Hirata (2016), que considera diaristas aqueles que trabalham em mais de um domicílio na semana ou que trabalham em único domicílio até duas vezes na semana.

Tendo por objetivo traçar um quadro mais amplo dos traços distintivos ou aproximativos das duas grandes categorias, ao longo do período selecionado são consideradas cinco dimensões de análise: características individuais; condições de trabalho; grau de proteção trabalhista e social; situação domiciliar; e grau de isolamento/pertencimento. Cada uma dessas dimensões privilegia a análise de indicadores selecionados. Por exemplo, na dimensão denominada "características individuais", englobam-se fatores como idade, gênero, naturalidade, cor ou raça, escolaridade e participação nos afazeres domésticos. O Quadro 1 ilustra as dimensões estudadas, bem como os indicadores contemplados em seu interior.

Este enfoque não busca categorizar a análise em grupos estanques, em si encerrados. Esta é apenas uma separação analítica, dado que as dimensões consideradas certamente apresentam comunicação, tais como as dimensões "situação domiciliar" e "condições de trabalho". A análise busca, sempre que aplicável, estabelecer as relações pontuadas na literatura entre esta e aquela dimensão, bem como com as demais. A próxima seção se dedica à descrição e discussão dessas dimensões.

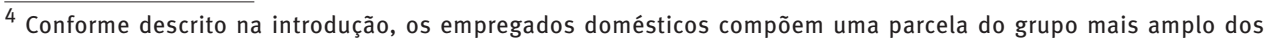
trabalhadores domésticos. No entanto, de forma a manter o paralelismo com o termo mais usual constante da literatura, referimo-nos a este grupo como empregados domésticos ao longo do texto.
} 
QUADRO 1

Dimensões e respectivos indicadores analíticos das ocupações de cuidados

\begin{tabular}{|l|l|}
\hline \multicolumn{1}{|c|}{ Dimensões } & \multicolumn{1}{c|}{ Indicadores } \\
\hline Características individuais & $\begin{array}{l}\text { Gênero, idade, naturalidade, cor/raça, escolaridade, participação nos } \\
\text { afazeres domésticos }\end{array}$ \\
\hline Condições de trabalho & $\begin{array}{l}\text { Jornada de trabalho semanal, rendimento mensal, número de } \\
\text { trabalhos na semana de referência }\end{array}$ \\
\hline Situação domiciliar & Posição no domicílio, coabitação com crianças ou idosos \\
\hline Grau de proteção trabalhista e social & $\begin{array}{l}\text { Contribuição para a previdência no trabalho da semana de } \\
\text { referência/ Posse de carteira de trabalho no trabalho da semana de } \\
\text { referência }\end{array}$ \\
\hline Pertencimento/Isolamento & $\begin{array}{l}\text { Associação a sindicato, tipo de sindicato a que se encontra } \\
\text { associado }\end{array}$ \\
\hline
\end{tabular}

\section{Cinco dimensões das ocupações de cuidados: entre aproximações e inflexões}

\section{Características individuais e evolução}

Se a denominação de cuidador parece implicar um rompimento - tanto no campo lexical ${ }^{5}$ quanto no que se refere às práticas e saberes subjacentes à ocupação - com a figura da "empregada doméstica polivalente" (ARAUJO, 2014), cabe-nos averiguar em que medida essas duas ocupações de cuidados aparentam se afastar ou se aproximar ao longo da primeira década e meia do século XXI. Nesta seção, buscamos, a partir de cinco dimensões analíticas, constantes do Quadro 1, cartografar o perfil evolutivo desses dois grupos ocupacionais, pontuando continuidades e inflexões.

Se de 2002 a 2015 o número absoluto de empregados domésticos apresentou modestas flutuações, a trajetória seguida pelo grupo dos cuidadores foi distinta. Nesse intervalo, o número de cuidadores de ambos os sexos dobrou. Com efeito, entre 2002 e 2015, o universo dos cuidadores passou de 643 mil para 1,3 milhão de ocupados (Gráfico 1). Esse movimento deveu-se ao aumento tanto do contingente de cuidadores domiciliares quanto daquele de cuidadores institucionais desde 2002, embora o primeiro deles siga como o mais numericamente representativo. De 2002 para 2015, o subgrupo dos cuidadores domiciliares mais do que dobrou - em 2015, perfazia 942,4 mil indivíduos, representando $74,5 \%$ do total de cuidadores -, enquanto o número de cuidadores institucionais variou de 219,3 mil para 322,2 mil, nesse mesmo período (ou cerca de um quarto do total de cuidadores). Já o conjunto dos empregados domésticos variou de 5,5 milhões para 5,0 milhões, entre 2002 e 2015.

\footnotetext{
$\overline{{ }^{5} \text { Ver Guimarães (2016) }}$ para uma análise a respeito da importância adquirida pelas expressões cuidado e cuidador(a).
} 
GRÁFICO 1

Número de empregados domésticos e cuidadores, segundo sexo

Brasil - 2002-2015

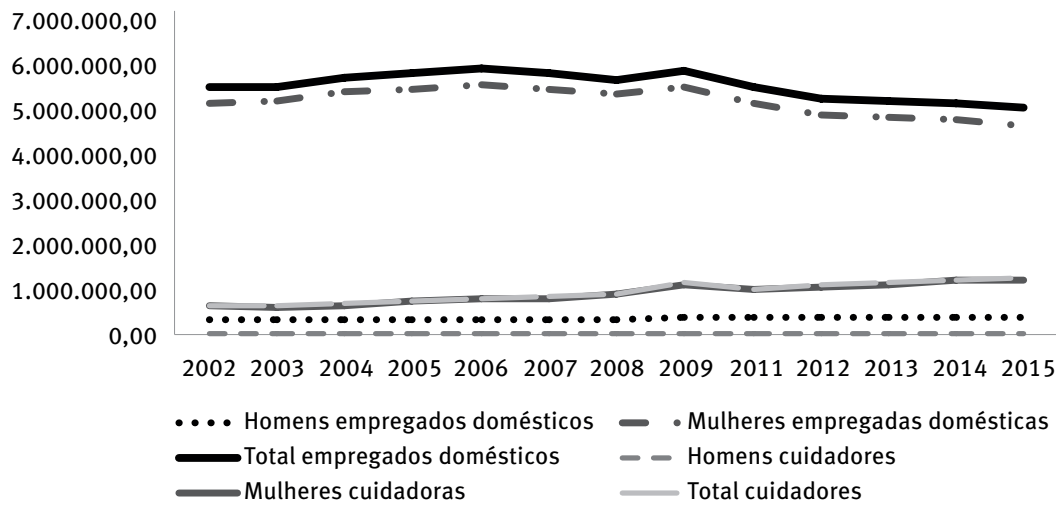

Fonte: IBGE. Pesquisa Nacional por Amostra de Domicílios (PNAD).

Em ambos os grupos foi possível igualmente observar o crescimento no montante de diaristas. No grupo dos empregados domésticos, os diaristas perfaziam 1,5 milhão de indivíduos, ou $27,8 \%$ do total de domésticos em 2002, passando para 2,4 milhões, em 2015 , o que correspondia a $47,1 \%$ do total de domésticos. 0 mesmo movimento ascendente foi notado no grupo de cuidadores. Em 2015, 144,5 mil cuidadores (ou 11,4\% do total) exerciam a atividade como diaristas, um acréscimo de 105,3 mil indivíduos em relação aos 6,1\% dos cuidadores (ou 39,2 mil indivíduos) de 2002. Essa trajetória parece refletir o movimento geral já detectado na literatura de aumento no total de diaristas em comparação ao de mensalistas (COSTA; BARBOSA; HIRATA, 2016). 0 fim da série em 2015 dificulta, contudo, que se capte uma maior sensibilidade dos dados aos efeitos da "PEC das domésticas”, discutida na seção de introdução. Um de seus efeitos indiretos seria a substituição dos trabalhadores domésticos mensalistas por diaristas. Pode-se notar, no entanto, um crescimento no total de domésticos diaristas entre 2013 e 2015 (aumento de 85,2 mil indivíduos ou de 2,9 pontos percentuais). A variação entre esses dois anos foi, entretanto, pequena para o grupo dos cuidadores diaristas. Houve uma variação negativa de 0,3 ponto percentual no peso dos cuidadores diaristas no total de cuidadores entre os dois anos, embora em valores absolutos o número de cuidadores tenha crescido em 8,5 mil. Ou seja, nesse intervalo de tempo, a ampliação do total de cuidadores foi superior ao de cuidadores diaristas.

Esses resultados evidenciam que, embora crescente para ambos os grupos, a alternativa de contratação de diaristas tem maior peso para o grupo dos domésticos: reiterando, em $2015,47,1 \%$ para o grupo dos domésticos contra $11,4 \%$ para o grupo dos cuidadores. Esse resultado pode estar mediado pelo vínculo contínuo e de longas jornadas que o ato de cuidar de outros, sobretudo indivíduos dependentes, envolve. Dessa forma, a ocupação do cuidador parece ser comparativamente menos sensível à alternativa de diaristas. 
O montante de indivíduos pertencentes a cada grupo e subgrupo não é estável, apresentando movimentos ascendentes e descendentes ao longo do período de análise, o que pode, dentre outros fatores, estar associado ao ciclo econômico brasileiro. Em particular, chama a atenção o pico no total de cuidadores e empregados domésticos em 2009 (Gráfico 1). No primeiro caso, o acréscimo foi unicamente devido ao aumento no total de cuidadores domiciliares. E, no interior dos dois principais grupos, o acréscimo deveu-se também à ampliação do total de diaristas, que oferecem uma maior flexibilização em momentos de ciclo econômico descendente, uma vez que não estão amparados pela legislação vigente para a categoria dos mensalistas. 0 conjunto de cuidadores diaristas mais do que dobrou no biênio 2008-2009, chegando a 159,1 mil indivíduos, ou 14\% do total dos cuidadores em 2009. Já o contingente de domésticos diaristas passou de 2,1 milhões para 2,4 milhões de pessoas, nesse mesmo período.

De forma geral, em ocupações como o emprego doméstico observa-se que, em momentos de retração econômica, como em 2009, há um aumento do número de ocupados, e não uma retração, confirmando seu caráter de emprego de "segunda zona” (DUSSUET, 2002), cujo direcionamento do trabalhador ocorre na ausência de alternativas ocupacionais. Os dados parecem reiterar esse seu caráter.

Em oposição, ao se concentrar no período de 2011 a 2013 - anos de reconhecida recuperação econômica e melhora expressiva no mercado de trabalho brasileiro - observa-se um declínio no número de ocupados no emprego doméstico, ao passo que a ocupação de cuidador mantém sua trajetória de ascensão. Nesse interregno, o total de cuidadores cresceu $13,7 \%$, enquanto o de diaristas cuidadores ampliou-se em $7,5 \%$, ao passo que no total de empregados domésticos diaristas houve queda de $0,9 \%$.

Adicionalmente, em diálogo com os resultados da literatura de gênero e mercado de trabalho, observa-se, igualmente nesta ocupação, um viés de gênero. No período investigado, as mulheres representavam, em média, $97 \%$ do grupo dos cuidadores, ficando 3 pontos percentuais acima do resultado encontrado para o grupo dos empregados domésticos, composto por $94 \%$ de mulheres. ${ }^{6} 0$ primeiro resultado torna-se evidente a partir da quase sobreposição das linhas “Total cuidadores" e "Mulheres cuidadoras”, no Gráfico 1. Conforme explícito na literatura em questão, as mulheres estão inequivocamente sobrerrepresentadas nas ocupações caracterizadas por uma quase extensão das atividades domésticas desempenhadas historicamente pelo gênero feminino. Igualmente, no imaginário coletivo, prevalece a representação cognitiva de que as atividades do cuidado - ainda que profissionalizadas - devem ser exercidas por mulheres, uma vez que os saberes requeridos para o exercício dessas atividades são, por sua vez, concebidos como algo natural ao universo do feminino (DEVETTER; JANY-CATRICE; RIBAULT, 2009).

\footnotetext{
${ }^{6}$ Diante desta evidência, referimo-nos a partir deste momento à ocupação no feminino. 0 mesmo será feito para o caso das empregadas domésticas.
} 
Ao marcador de gênero somam-se outras características consideradas relevantes para os nossos grupos de interesse. Conforme pode ser observado a partir de Avril (2006) e Devetter e Rousseau (2011), diante da baixa ou ausente qualificação, características individuais como ser mulher, possuir determinada idade e apresentar experiências prévias pessoais com o "cuidar" se convertem em um ativo no mercado de trabalho dos cuidados. Dessa forma, além do marcador de gênero, o atributo da idade é também evidenciado. Dos grupos etários analisados, ${ }^{7}$ as cuidadoras se concentram principalmente na faixa de 36 a 50 anos (33,8\% em 2015), embora não sejam desprezíveis os percentuais de jovens nas faixas de 15 a 18 e 19 a 25 anos, bem como de adultos de 26 a 35 e 51 a 64 anos nesta ocupação. Em 2015, a média de idade entre as cuidadoras era de 39 anos. Este resultado é igualmente observado no grupo das empregadas domésticas, com alta concentração na faixa de 36 a 50 anos (45,7\% em 2015) e uma média de idade de 43 anos em 2015. Contudo, deve-se salientar que a participação de jovens adolescentes (15 a 18 anos) no grupo das empregadas domésticas (4,1\% na média do período 2002-2015) é menos representativa do que no das cuidadoras (14,9\%). Esse indicador nos faz indagar a natureza do cuidado ofertado por essas jovens, se relacionado à atenção a crianças, idosos ou jovens. Contudo, a base de dados não permite desagregar a natureza do cuidado oferecido por essas adolescentes.

Tais evidências não são estanques. Observa-se também, ao longo dos anos, um processo de envelhecimento de ambas as categorias. Entre 2002 e 2015, a idade média das empregadas domésticas se elevou em 7,8 anos, número semelhante aos 7 anos experimentados pelas cuidadoras. Este fato pode ser um indicativo da busca, por parte de mulheres mais jovens - e mais escolarizadas -, de outras ocupações, justamente em um período em que o ciclo econômico expansivo proporcionou novas oportunidades em termos de mercado de trabalho; ou, ainda, pode apontar a opção pelo prolongamento da permanência no ambiente escolar/acadêmico. Este indicador também parece refletir em alguma medida o movimento mais geral de envelhecimento da população economicamente ativa (PEA) como resultado do processo de transição demográfica (SABOIA, 2014).

Aliada ao aumento da idade, há também a elevação da escolaridade média de ambos os grupos, que pode ser verificada nos Gráficos 2 e 3. Esta modificação também acompanha de certa forma a melhora nos níveis de escolaridade para toda a população, e em especial para as mulheres, nos anos em questão (IBGE, 2015). Em 2015, as cuidadoras possuíam, em média, 9,4 anos de estudo, contra 7,5 anos das empregadas domésticas e a média de 8,1 anos no início da série. Dentre as cuidadoras, aquelas que trabalhavam em instituições formavam um subgrupo mais escolarizado. Em 2015, elas possuíam 10,7 anos de estudo, um aumento de dois anos em relação ao início da série de dados. As cuidadoras domiciliares apresentavam uma média de 8,9 anos de estudo em 2015.

\footnotetext{
${ }^{7}$ Os grupos etários analisados são os de 15 a 18 anos (ambos inclusos), 19 a 25 anos (ambos inclusos), 26 a 35 anos (ambos inclusos), 36 a 50 anos (ambos inclusos), 51 a 64 anos (ambos inclusos) e 65 anos ou mais.
} 
GRÁFICO 2

Distribuição das cuidadoras, segundo grupos de anos de estudo Brasil - 2002-2015

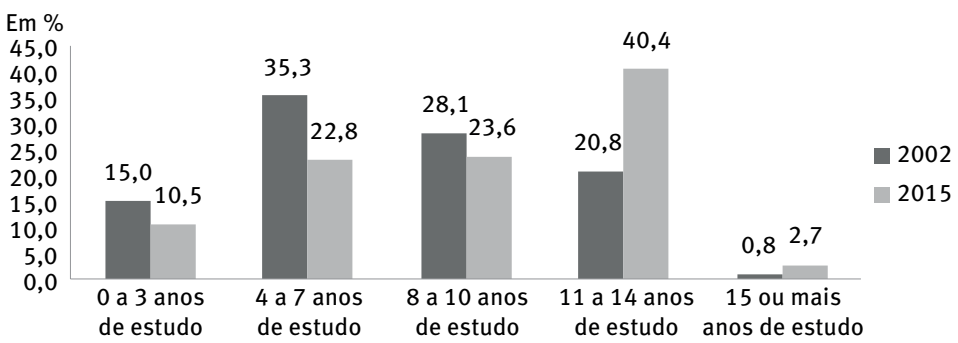

Fonte: IBGE. Pesquisa Nacional por Amostra de Domicílios (PNAD).

\section{GRÁFICO 3}

Distribuição das empregadas domésticas, segundo grupos de anos de estudo Brasil - 2002-2015

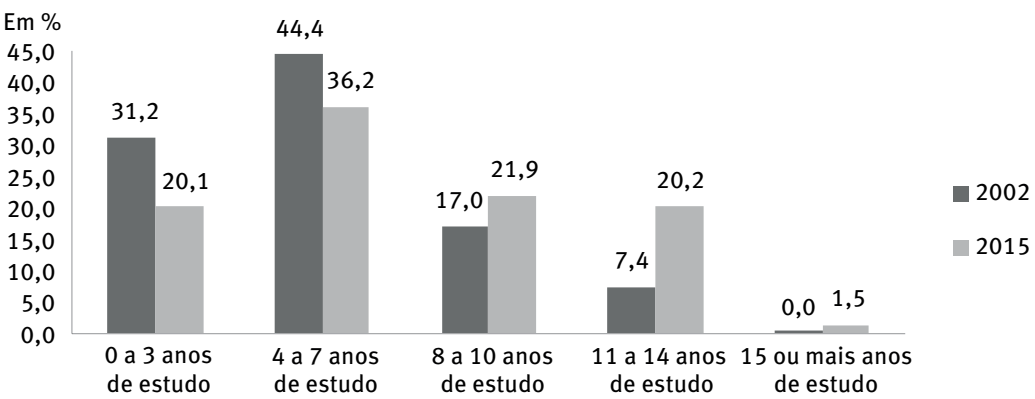

Fonte: IBGE. Pesquisa Nacional por Amostra de Domicílios (PNAD).

Observa-se que, em 2002, a faixa de 4 a 7 anos de estudo era predominante para ambas as categorias. Entretanto, desde 2011, há uma inflexão no grupo das cuidadoras e passa-se a assistir uma preponderância relativa daquelas com 11 a 14 anos de estudo. Esse cenário se estende até 2015. Tal movimento foi puxado, em maior medida, pelas cuidadoras institucionais, que desde 2003 se concentram em maioria nessa faixa de anos de estudo. Em 2003, 32,4\% das cuidadoras institucionais possuíam de 11 a 14 anos de estudo e, em 2015 , esse percentual era de $55,9 \%$. No caso das empregadas domésticas, o grupo de 4 a 7 anos permanece como o mais relevante em todo o período de análise. Ressalta-se que este resultado torna-se relevante diante da nova exigência em relação à escolaridade mínima necessária ao exercício da atividade de cuidadora, cuja concepção atual, por lei, demanda o ensino fundamental completo. ${ }^{8}$

Assim como o indicador de grupos de anos de estudo, também foi possível observar uma inflexão no indicador de cor ou raça. Isto é, ainda que, corroborando o viés de raça do emprego doméstico, em 2015, 58,3\% das cuidadoras tenham se autodeclarado pretas ou pardas, verifica-se que, a partir de 2007, houve uma alteração neste indicador. Até

\footnotetext{
8 Para uma revisão abrangente sobre a regulamentação da profissão de cuidador, realizada, contudo, antes da regulamentação da legislação, ver Debert e Oliveira (2015).
} 
aquele ano, quando $51,8 \%$ das cuidadoras se autoidentificaram como pretas ou pardas, a predominância era de indivíduos que se autodeclararam brancos, o que não ocorreu no grupo das empregadas domésticas, em que a predominância de indivíduos pretos e pardos se manteve por todo o período analisado. Assim como no caso das cuidadoras, este indicador revela uma trajetória ascendente da proporção de empregadas pretas e pardas, passando de $56,5 \%$ para 64,7\%, entre 2002 e 2015 (Gráfico 4).

Este resultado pode ser em alguma medida reflexo de um aumento geral no número de indivíduos que passaram a se autodeclarar pretos ou pardos ao longo dos últimos anos (PINHEIRO et al., 2008; PAIXÃO; ROSSETTO, 2011). Ainda segundo as PNADs 2002 e 2015, o mesmo indicador cresceu 8,1 pontos percentuais para as mulheres da população em geral, passando de $43,5 \%$ para $51,6 \%$. Ou seja, ainda que as empregadas domésticas o fizessem em maior grau, as cuidadoras também se identificavam proporcionalmente mais do que a média populacional como pretas ou pardas. Contudo, a inflexão observada não é válida para o caso das cuidadoras institucionais, que seguem majoritariamente brancas, embora em menor percentual com relação a 2002. Em 2015, o percentual de cuidadoras institucionais brancas era de $51,2 \%$. Esse fator pode ter impactado a subdeclaração nos anos iniciais de análise para o grupo das cuidadoras.

\section{GRÁFICO 4}

Proporção de empregadas e cuidadoras, segundo a cor ou raça

Brasil - 2002-2015

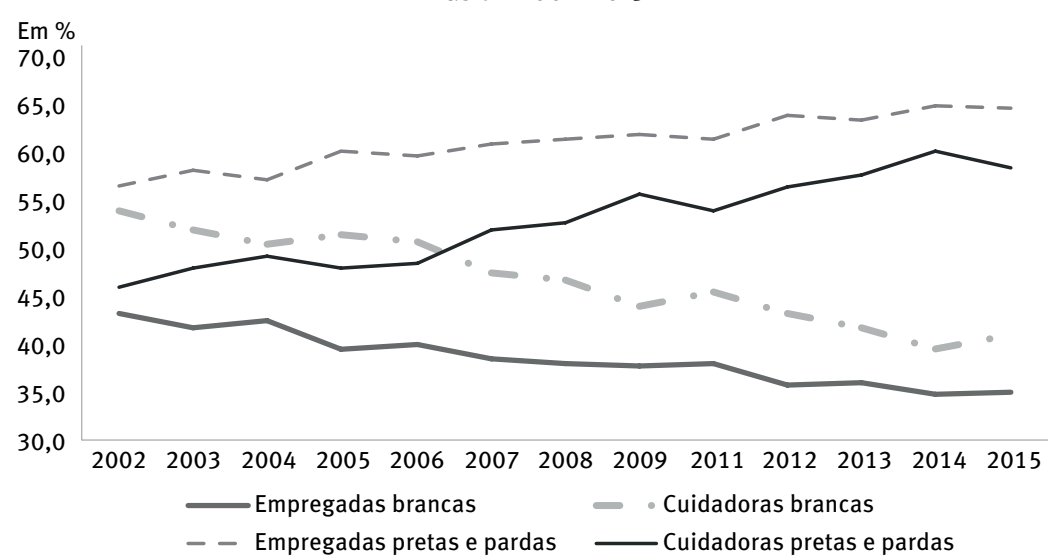

Fonte: IBGE. Pesquisa Nacional por Amostra de Domicílios (PNAD).

Uma vez que já investigamos o caso geral, cabe-nos questionar se a alteração observada na faixa predominante de anos de estudo ocorreu em todos os grupos etários e de cor ou raça. Em 2011, houve predominância do grupo de 11 a 14 anos de estudo para as cuidadoras de 19 a 25 anos de idade (52\%) e de 26 a 35 anos (45,4\%). As cuidadoras de 36 a 50 e 51 a 64 anos concentravam-se em sua maioria na faixa de 4 a 7 anos de estudo, com percentuais correspondentes a, respectivamente, $32,1 \%$ e $30,8 \%$, em perfil semelhante ao das domésticas. Aquelas de idade igual ou superior a 65 anos possuíam escolaridade 
inferior, concentrando-se principalmente na primeira faixa de escolaridade, de 0 a 3 anos de estudo (45,8\%).

Cabe observar, no entanto, que em 2011, com relação a 2002, todos os grupos etários aumentaram sua participação no grupo escolar de 11 a 14 anos, em particular aquele de 26 a 35 anos. Em 2015, as faixas etárias de 19 a 25 e de 26 a 35 anos seguem com maior representação do grupo de 11 a 14 anos de estudo. Chama a atenção, contudo, o fato de que, neste último ano, as cuidadoras com 11 a 14 anos de estudo se tornaram o grupo predominante também dentre as cuidadoras de 36 a 50 anos de idade. Estas mudanças parecem acompanhar um movimento que ocorre no Brasil, de substituição de gerações menos escolarizadas por gerações que apresentam maiores níveis de escolaridade (IBGE, 2015), e os dados desagregados por cor ou raça apontam para o mesmo caminho.

No que tange à participação de cada grupo de cor ou raça nas faixas de escolaridade, observa-se que, em 2002, a faixa de 11 a 14 anos não era a mais representativa dentre as cuidadoras de nenhum dos grupos considerados (indígena, branca, preta, parda e amarela). Contudo, em 2007, esse era o grupo de maior concentração das cuidadoras que se autodeclararam pretas. Das 97,2 mil cuidadoras que se autodeclararam pretas, $34,4 \%$ possuíam de 11 a 14 anos de estudo. Concentrando-nos em 2011, a faixa de escolaridade de 11 a 14 anos também é a mais relevante para o grupo das cuidadoras brancas (34,3\%), pretas (35,7\%) e pardas (28,2\%). Em 2015 esse perfil se mantém, passando a ser válido para todos os grupos de cor ou raça.

Para além dos indicadores de gênero, idade e escolaridade, parece-nos relevante analisar em que medida a ocupação de cuidadora é marcada pela alta participação de migrantes internas em sua composição, traço característico do emprego doméstico brasileiro. Os dados apontam que, bem como as empregadas domésticas, no período 2002-2015, percentual representativo de cuidadoras (média de $21,5 \%$ versus $24,4 \%$ no caso das empregadas domésticas) é proveniente de outras unidades da federação, sobretudo da região Nordeste. Logo, pouco mais de um quinto das cuidadoras ou quase um quarto das domésticas exercem a atividade do cuidado em estado distinto daquele de sua origem.

Esta evidência pode estar associada à ainda alta acessibilidade relativa que a ocupação oferece. Na concepção vigente durante nosso período de análise, a atividade profissional em questão não requer necessariamente fatores outros além de experiência prévia com o cuidado - mesmo que informal - ou disponibilidade para seu exercício, podendo, dessa forma, atrair indivíduos de menor escolaridade, qualificação e migrantes, cujas chances de inserção no mercado de trabalho são relativamente menores.

Uma vez que os perfis já foram traçados, cabe-nos investigar como ambas as categorias se comportaram no mercado de trabalho brasileiro durante o período estudado. A seguir, são analisados os traços de cuidadoras e empregadas domésticas pelo ângulo das dimensões de condições de trabalho e grau de proteção trabalhista e social, tendo como pano de fundo os resultados alcançados nessa seção. 


\section{Condições de trabalho e proteção trabalhista e social}

A legislação brasileira permite que trabalhadores individuais - tais como empregadas domésticas e cuidadoras - contribuam para a previdência social sem que necessariamente possuam a carteira de trabalho assinada. Essa possibilidade dá acesso aos trabalhadores a um tipo de proteção social primária, como a aposentadoria por velhice e o auxílio por acidente de trabalho. Entretanto, estes continuam privados de direitos trabalhistas completos, os quais apenas os trabalhadores com carteira têm acesso, como o 13ํㅗ salário e o recebimento de horas extras. Esta restrição faz da opção contributiva sem acesso à carteira de trabalho uma espécie de formalização "segundo melhor", enquanto a posse de uma carteira de trabalho garantiria um grau de formalização completo (KERSTENETZKY; MACHADO, 2018).

Não obstante, observa-se que a crescente formalização foi verificada de forma geral na economia, a partir das políticas de mercado de trabalho adotadas neste interim (MOURA; BARBOSA FILHO, 2014; KERSTENETZKY; MACHADO, 2018). Para as categorias aqui analisadas, em especial, somam-se a este fator os direitos adquiridos a partir da aprovação da PEC do emprego doméstico, cujo efeito se estendeu às cuidadoras. Dentre tais direitos se enquadra o de registro em carteira.

No que diz respeito à formalização do tipo "primeiro melhor”, isto é, aquela em que há posse de carteira de trabalho assinada, observou-se uma melhora para ambos os grupos no período analisado, ainda que o registro em carteira represente a realidade de uma minoria das empregadas e das cuidadoras. Estas duas categorias partiram de patamares parecidos para a posse de carteira em 2002 (26,6\% das empregadas e 24,5\% das cuidadoras) e chegaram a 2015 com praticamente a mesma proporção de carteira assinada, com respectivamente $31,9 \%$ e $31,1 \%$.

No que se refere somente à contribuição previdenciária, no trabalho que exerciam no momento da pesquisa, $42,1 \%$ das cuidadoras contribuíam para a previdência em 2015 , contra $28 \%$ em 2002, um aumento de 14,1 p.p. Esses percentuais são bem próximos daqueles do grupo das domésticas: 28,8\% em 2002 e 41,1\% em 2015.

A despeito da relativamente baixa proteção trabalhista e social - em termos comparativos, o percentual de ocupados de 15 anos ou mais que contribuíam para a previdência foi de $54,9 \%$ na média do período 2002-2015, ou de 62,7\% em 2015 -, ganha destaque a alta disponibilidade temporal que estas mulheres ofertam uma vez ocupadas. Não obstante o fato de que, no período 2002-2015, para $97,1 \%$ das cuidadoras e $97,6 \%$ das empregadas domésticas a ocupação principal seja a única na semana de referência, as longas jornadas parecem ser características na ocupação. Isto é, nos anos analisados, percentual sempre superior a $60 \%$ das cuidadoras e, em média, 55,3\% das empregadas domésticas possuíam carga horária igual ou superior a 40 horas semanais no trabalho único ou principal na semana, o que configura uma jornada média de 40,4 horas e de 35,4 horas no período 2002-2015, respectivamente. No grupo das cuidadoras, essa 
média é comparativamente menor para o subgrupo das cuidadoras institucionais $(37,4$ horas na média dos anos considerados). Para as cuidadoras domiciliares, a jornada média foi de 41,3 horas.

A diferença de cinco horas na jornada média entre os dois principais grupos merece destaque. Dois pontos em especial podem ser acionados como explicativos: a atenção contínua demandada pelas atividades do cuidado; e o alto - e crescente - peso das diaristas, sobretudo no grupo das domésticas, conforme discutido na seção anterior. No primeiro caso, o resultado pode ser respaldado pela própria demanda temporal exigida pelo ato de cuidar. Para as cuidadoras de idosos, por exemplo, requer-se uma atenção contínua com relação ao membro dependente, o que desemboca na contratação, por parte do indivíduo cuidado e/ou de sua família, de profissionais disponíveis para o exercício de longas jornadas. Araujo (2014), a partir da investigação de uma empresa de intermediação de cuidadoras de idosos no Rio de Janeiro, sublinha a preferência pela contratação de cuidadoras no regime 48 horas/ 48 horas. No segundo caso, observa-se que o crescente peso das diaristas, de menores jornadas médias semanais, pode se configurar como uma explicação adicional para a diferença notada entre os dois grupos estudados. Em 2015, a jornada de trabalho média das domésticas diaristas era de 24,6 horas semanais, sendo que a média para o período 2002-2015 foi de 27,1 horas. Resultado consideravelmente inferior às 35,4 horas encontradas para o total das domésticas.

De forma simplificada, o tempo social e as articulações que lhe são próprias podem ser subdivididos em trabalho remunerado e trabalho não remunerado. Percebe-se que o alto número de horas dedicadas ao trabalho remunerado não implica, contudo, uma diminuição no número de horas dedicadas às atividades do ambiente doméstico no qual estão inseridas estas mulheres, o que é, em geral, uma tônica do trabalho feminino (PÉRIVIER; SILVERA, 2010). As, em média, 90\% das cuidadoras e empregadas domésticas que afirmaram se ocupar dos afazeres domésticos na semana de referência gastavam cerca de 22 horas semanais com tais atividades. Em termos numéricos, isto representa que, entre trabalho remunerado e trabalho não remunerado, cuidadoras e domésticas despendiam em média 62,2 e 57,6 horas semanais, respectivamente.

A expressiva carga temporal de trabalho não parece, contudo, traduzir-se em termos salarias. Em 2015, conforme pode ser observado no Gráfico 5, o rendimento médio do trabalho principal para as cuidadoras equivalia a $R \$ 785,00$, valor este próximo ao auferido pelas empregadas domésticas (R\$ 752,54). No contingente das cuidadoras, o rendimento das que trabalham em instituições se diferencia daquele das cuidadoras domiciliares. Em 2015, o rendimento médio das cuidadoras domiciliares correspondia a $R \$ 741,60$, valor inferior em $R \$ 171,60$ aos $R \$ 913,18$ auferidos pelas cuidadoras institucionais. Em termos comparativos, o salário mínimo nominal em setembro de 2015 equivalia a $R \$ 788,00$, valor este superior em $0,4 \%$ àquele auferido pelas cuidadoras $\mathrm{e}$ em $4,7 \%$ ao recebido mensalmente pelas empregadas domésticas. 
GRÁFICO 5

Rendimento médio do trabalho principal de empregadas domésticas e cuidadoras Brasil - 2002-2015

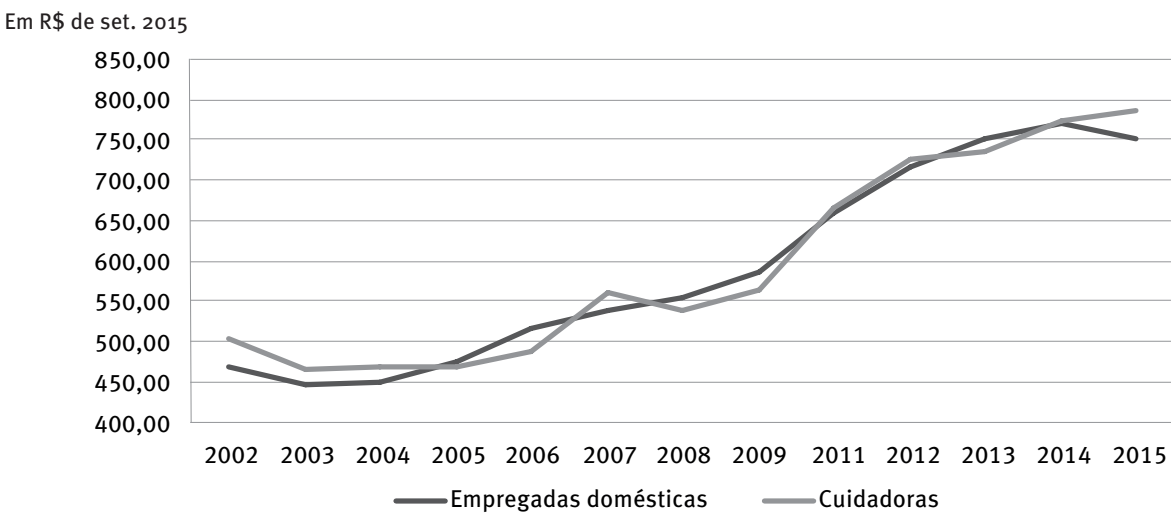

Fonte: IBGE. Pesquisa Nacional por Amostra de Domicílios (PNAD).

Nota: Rendimentos deflacionados para setembro de 2015, segundo índice proposto por Corseuil e Foguel (2002), baseado no INPC.

Entre 2002 e 2015, o rendimento médio do trabalho principal de empregadas e cuidadoras sofreu valorização de, respectivamente, $60,1 \%$ e $55,5 \%$, em um movimento que parece ter acompanhado o processo de valorização dos salários verificado no período. Apesar do crescimento do indicador, ainda assim a variação verificada para ambas as categorias se encontra abaixo da valorização real do salário mínimo no período $(81,6 \%)$. Isto é, tal resultado, apesar de espelhar um aumento do poder de compra de ambas as categorias, em certa medida também reforça a baixa valorização monetária destas ocupações.

Tendo em vista as diferentes jornadas de trabalho remunerado desses grupos, o indicador de rendimento médio pode ser uma medida imperfeita. Nesse caso, o indicador de rendimento/hora parece melhor atender à comparação pretendida. Uma vez traduzido em rendimento/hora de trabalho remunerado, as cuidadoras recebiam valor levemente inferior àquele das domésticas - R\$ 5,20 (cuidadoras) e R\$ 6,00 (domésticas) em 2015.

Significativas são as variações por regiões. Embora o rendimento/hora tenha variado positivamente entre 2002 e 2015 em todas as regiões para as duas categorias ocupacionais, o Norte ${ }^{9}$ e Nordeste apresentam os resultados mais baixos para esse indicador. Em 2015, no Nordeste, as empregadas domésticas auferiam $R \$ 4,10$ de rendimento/hora e as cuidadoras $\mathrm{R} \$ 3,50$. No Norte, os valores correspondiam a $\mathrm{R} \$ 4,80$ e $\mathrm{R} \$ 3,90$, respectivamente. Em contraponto, no Sul foram observados os maiores rendimentos/hora para ambos os grupos: $R \$ 7,50$ para as domésticas e $R$ \$ 5,80 para as cuidadoras, naquele mesmo ano.

Em análise para o caso francês, Devetter, Jany-Catrice e Ribault (2009) igualmente salientaram o baixo valor monetário auferido na esfera dos cuidados profissionais. De acordo com os autores, este resultado pode ser interpretado pela ótica da reduzida valoração

\footnotetext{
${ }^{9}$ Reitera-se que consideramos apenas o Norte urbano nessa análise, com a finalidade de compatibilizar os dados ao longo de toda a série de dados, conforme discutido na primeira seção.
} 
simbólica atribuída à ocupação, uma vez que, por ser exercida preponderantemente por mulheres e concebida como uma atividade feminina por excelência, esta é também compreendida como um trabalho "que qualquer um poderia fazer" (DUSSUET, 2002).

Voltando à nossa pergunta central, isto é, quais os traços distintivos entre cuidadoras e domésticas, merece destaque uma significativa alteração no tipo de ocupação exercida na atividade secundária, quando existente, na categoria das cuidadoras. ${ }^{10} \mathrm{Em} 2002$, estas encontravam-se ocupadas notadamente em atividades de serviços como as de comerciantes, vendedoras, ou ambulantes, ou em ocupações dos ramos alimentício, de vigilância, costura, lavanderia e tinturaria e limpeza, ou possuíam mesmo um segundo vínculo como cuidadora (9,2\%). Em 2014, destacou-se como segundo vínculo empregatício a ocupação de trabalhadora nos serviços domésticos.

Percebe-se aqui, portanto, como essas categorias se interpenetram, isto é, para $16 \%$ das cuidadoras que em 2014 possuíam uma segunda ocupação na semana de referência, esta era a de trabalhadora nos serviços domésticos. Tal ocupação, conforme destacado na introdução, engloba uma miríade de itens, como arrumadeira, auxiliar nos serviços gerais, camareira, caseira, lavadeira, faxineira, todos esses no serviço doméstico, e a própria empregada doméstica. ${ }^{11} \mathrm{Em} 2015$, essa foi ainda uma ocupação relevante, a terceira mais importante entre as cuidadoras que possuíam uma segunda ocupação. Com efeito, $7,1 \%$ das cuidadoras encontravam-se ocupadas em serviços domésticos em sua segunda ocupação nesse ano. Ainda, nesse mesmo ano, para 4,7\% delas, sua segunda ocupação era também a de cuidadora.

Em resumo, baixo grau de proteção trabalhista e social, baixas remunerações mensais e longas jornadas descrevem de forma geral nossas ocupações de análise. Contudo, mudanças podem ser notadas, em particular o aumento da formalização da população brasileira, que se estendeu também ao grupo das cuidadoras e domésticas. Contudo, esse exame nos parece, ainda, deficitário das relações entre o cenário domiciliar e a inserção profissional desses grupos, bem como uma análise do isolamento dos mesmos. Abordamos esse tópico nas seções seguintes.

\section{Situação domiciliar}

Considerando a situação domiciliar das cuidadoras, pode-se observar o expressivo e crescente percentual daquelas que se declaram pessoas de referência. Em 2015, do universo de 1,3 milhão de cuidadoras, 36,3\% se autodeclararam pessoas de referência no domicílio, resultado superior em 17,5 pontos percentuais ao observado em 2002 e maior do que o das cuidadoras institucionais, entre as quais 31,7\% eram pessoas de referência em seus domicílios em 2015. De igual forma, observa-se um decréscimo no percentual

\footnotetext{
${ }^{10}$ Cabe destacar que era diminuto (menos de $3 \%$ ) o percentual de cuidadoras que possuíam duas ou mais ocupações na semana de referência.

${ }^{11}$ Reitera-se, contudo, que este percentual representa diminutos casos na amostra, uma vez que é baixo o percentual de cuidadoras que possuíam mais de uma ocupação na semana de referência.
} 
de cuidadoras identificadas como filhas em seus respectivos domicílios. Atribui-se este movimento notadamente a dois fatores: o crescimento geral no número de mulheres que passaram a se declarar pessoa de referência (IBGE, 2014); e o próprio aumento da idade média das cuidadoras, conforme pontuado anteriormente. 0 mesmo é válido no caso do segundo grupo ocupacional analisado. No último ano investigado, 45,0\% das domésticas se caracterizavam como pessoa de referência do domicílio, contra 26,3\% em 2002.

Chama a atenção a diferença entre o percentual de empregadas domésticas e de cuidadoras que se autodeclararam pessoas de referência em 2015 (8,7 p.p.). Duas possíveis explicações podem ser elencadas: uma primeira hipótese para a maior prevalência de empregadas domésticas como pessoas de referência em comparação às cuidadoras é a idade média mais alta do primeiro grupo em relação ao segundo; e uma segunda hipótese reside na composição dos dois grupos. Ainda que tenha havido um movimento de aumento do percentual de cuidadoras e domésticas autodeclaradas pretas ou pardas, sobretudo no grupo das cuidadoras, o percentual de pretas e pardas é ainda relativamente superior no grupo das domésticas (Gráfico 4).

Conforme estudo do Dieese (2013), dentre as domésticas pretas e pardas há uma maior participação relativa daquelas que se autoidentificam como pessoas de referência com relação às domésticas não pretas e pardas. Dessa forma, por uma diferença de composição, pode-se esperar que o grupo representado em maior percentual por mulheres pretas e pardas (o das domésticas) seja aquele no qual se observa uma sobreclassificação relativa de pessoas de referência no domicílio. Reiterando, em 2015, se autodeclararam pretas ou pardas $58,3 \%$ das cuidadoras e $64,7 \%$ das domésticas.

Os dados das PNADs evidenciam que, em 2002, 26,8\% das empregadas domésticas pretas e pardas eram pessoas de referência no domicílio, percentual que equivalia a $25,6 \%$ entre as não pretas e pardas. Em 2015, esses valores correspondiam a 45,6\% e 44,0\%, respectivamente. Entre as cuidadoras, $15,4 \%$ das que se autodeclararam pretas e pardas e $21,8 \%$ das não pretas e pardas eram pessoas de referência em 2002. Tais percentuais eram de, respectivamente, $36,1 \%$ e $36,7 \%$, em 2015 . Ou seja, para o grupo das cuidadoras ocorre uma inversão - nele, há uma maior participação relativa de não pretas e pardas que são pessoas de referência comparativamente às pretas e pardas.

À evidência de aumento de domésticas e cuidadoras que ocupavam a posição de pessoas de referência em seus domicílios soma-se o fato de que, na média do período 2002-2015, em 43,1\% dos domicílios nos quais as cuidadoras residem e em 45,8\% dos domicílios de residência das empregadas domésticas, coabitava ao menos uma criança ou idoso. ${ }^{12}$ Este indicador torna-se relevante na medida em que pode representar uma demanda de cuidado intradomiciliar, sobretudo considerando-se a sobrerrepresentação deste grupo ocupacional em posições de centralidade no domicílio, como a de pessoa de referência, o que pode em certa medida conferir às mesmas a responsabilidade por

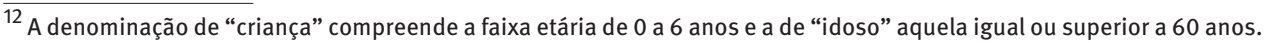


membros dependentes do domicílio. Ademais, conforme salientado pela literatura de cuidados e mercado de trabalho, as necessidades de cuidados domiciliares com membros dependentes do domicílio se convertem em entrave adicional à entrada em atividades remuneradas (SORJ; FONTES, 2012).

\section{Isolamento}

A despeito do fato de que em pesquisas domiciliares e em exercícios quantitativos como o que propomos seja difícil analisar dimensões simbólicas e/ou psicológicas, buscamos aqui, sucintamente, observar o grau de pertencimento/isolamento das ocupações dos cuidados a partir da participação sindical.

Para tal, tomamos a expressão isolamento em empréstimo a Devetter, Jany-Catrice e Ribault (2009). No referido trabalho, os autores, ao tratarem do reconhecimento jurídico e simbólico das ocupações de cuidados, definem o isolamento pela falta de colegas de trabalho ou de formas de representação coletiva. Com efeito, ainda que às ocupações em questão seja creditado um alto conteúdo relacional - destacadamente pronunciado nas ocupações de serviços -, tal representação, ao menos no caso das ocupações de cuidados, deve ser, em certa medida, ponderada. Isso deve-se ao fato de que tais atividades são, por vezes, desempenhadas em total isolamento, cujo contato com seu empregador se resume eventualmente a instruções gerais passadas no início ou ao fim de sua jornada (DEVETTER; ROUSSEAU, 2011). Como consequência indireta do isolamento, Devetter, Jany-Catrice e Ribault (2009) pontuam uma baixa taxa de participação sindical.

Não surpreendentemente, esta evidência reverbera no indicador de filiação sindical. Em média, para o período 2002-2015, apenas 3,5\% das cuidadoras e 2,2\% das empregadas domésticas declararam participar de algum sindicato, percentuais contrastantes com a taxa de sindicalização para o total dos ocupados de 15 anos ou mais de idade, que era de $17,8 \%$. Cabe notar que, no grupo das cuidadoras, o indicador é influenciado pela participação sindical das cuidadoras institucionais, que, na média do período 2002-2015, eram em $9,8 \%$ filiadas a sindicatos.

Este resultado, aliado ao aspecto insular destas atividades, pode adicionalmente ser analisado pelas longas jornadas semanais a que estão submetidos ambos os grupos ocupacionais, bem como à sobrerrepresentação feminina entre cuidadoras e empregadas domésticas. Tendo em vista que, entre as mulheres, comparativamente ao gênero masculino, a participação política é significativamente menos representativa (BIROLI, 2016), pontua-se que este fator pode impactar o dado observado.

No que se refere especificamente às cuidadoras profissionais, o processo de inserção sindical pode igualmente ser tolhido pelo não reconhecimento da profissão até o último ano analisado, o que desembocaria, por conseguinte, em uma dificuldade adicional de mobilização política ou mesmo na informação ou decisão de a qual sindicato se filiar. A desagregação por tipo de sindicato não nos auxilia, contudo, a elucidar tal "nebulosidade" 
da representação sindical - dentre o irrisório grupo das cuidadoras que declararam pertencer a sindicato, a parcela mais representativa é daquelas que disseram pertencer ao grupo sindical genérico denominado "empregados urbanos". Já no caso das domésticas, a maior concentração ocorre no grupo dos "trabalhadores rurais". ${ }^{13}$

\section{Considerações finais}

Desde os anos iniciais da primeira década do século XXI, podemos avaliar a conformação e desenvolvimento de um novo grupo ocupacional, o das cuidadoras profissionais. 0 termo "novo" pode descrever tanto sua incorporação às estatísticas nacionais desde a inclusão na Classificação Brasileira de Ocupações (CBO) da ocupação de cuidados, quanto o fato de, sobretudo a partir dos anos 2000 , ter se tornado corrente no vocabulário nacional.

Contudo, quão distinta é esta categoria ocupacional com relação à das empregadas domésticas, tendo em vista que desta última, e de sua reconhecida polivalência, ela "herda" parte de suas atividades? Ao longo do exame proposto buscamos responder a essa questão. Em especial, durante o período 2002-2015, esses dois grupos apresentaram maiores aproximações ou inflexões em relação a seus perfis?

A partir do recurso a cinco dimensões de análise, os dados apresentados neste trabalho sugerem uma aproximação ao longo dos anos entre o perfil das trabalhadoras domésticas e o das profissionais de cuidado em praticamente todos os indicadores analisados, ainda que o primeiro siga como o grupo majoritário. Ambas as ocupações são marcadas pela precariedade. Predominantemente exercidas por mulheres pretas e pardas, contam com baixo nível de remuneração e de proteção social e alta carga horária de trabalho remunerado, somada a extensas jornadas não remuneradas.

As inflexões mais notáveis são as observadas nos indicadores de cor/raça e de escolaridade. Ao contrário das empregadas domésticas, que ao longo de todo o período são majoritariamente pretas e pardas, o mesmo não é verdadeiro para o conjunto das cuidadoras. Para estas, apenas a partir de 2007 o percentual de cuidadoras pretas e pardas se torna relativamente predominante. No que se refere à escolaridade, a inflexão ocorre em 2011. A partir deste ano, as cuidadoras passaram a figurar sobretudo no grupo de escolaridade de 11 a 14 anos de estudo.

Curiosamente, a escolaridade é a única característica socioeconômica que de fato as diferencia, sendo consideravelmente mais alta para o grupo das cuidadoras e, entre estas, mais elevada para o subgrupo das cuidadoras institucionais.

Até o momento, este fato não se converteu em maior remuneração no mercado de trabalho, o que reforça a hipótese de que a procura pela ocupação de cuidadora se daria mais pelo status social conferido por essa profissão em relação à de empregada doméstica. Possíveis cenários se encontram em aberto, em parte devido às recentes mudanças

\footnotetext{
${ }^{13}$ As demais opções de resposta são sindicato de trabalhadores autônomos, de trabalhadores avulsos, de profissionais liberais e outros sindicatos.
} 
na legislação, como a "PEC das domésticas" ou o PLC 11/2016. Uma tendência que se delineia até o último ano disponível em nossa série de dados é o aumento do percentual de diaristas entre as domésticas e cuidadoras, principalmente no primeiro grupo. Mas pode-se pensar em outros cenários. No futuro, inclusive, a exigência de uma qualificação formal mínima para as cuidadoras, prevista agora em lei, em oposição à ausência desta para as trabalhadoras domésticas, também pode significar um reforço à ideia de que as cuidadoras poderiam diferenciar-se das domésticas pelo status da profissão, uma vez que o requisito da escolaridade tornaria o acesso a essa ocupação mais restritivo. 0 quão recentes são essas mudanças em relação ao fim da série de dados em 2015 nos traz maiores indagações do que afirmações peremptórias. Contudo, essa se torna também uma área fecunda para novos estudos sobre o tema.

\section{Referências}

ARAUJO, Anna Bárbara. As empresas de cuidado de idosos, as cuidadoras e as demandas do trabalho: continuidades e descontinuidades entre a esfera familiar e a esfera do mercado. In: ENCONTRO ANUAL DA ANPOCS, 38, 2014. Anais [...].Caxambu: Anpocs, 2014.

AVRIL, C. Aide à domicile pour personnes âgées: un emploi-refuge. 2006. Mimeografado.

BIROLI, Flávia. Divisão sexual do trabalho e democracia. Dados, v. 59, n. 3, p.719-754, set. 2016.

BRASIL. Presidência da República. Casa Civil. Lei n. 5.859, de 11 de dezembro de 1972. Dispõe sobre a profissão de empregado doméstico e dá outras providências. Brasília, DF, 1972.

BRASIL. Presidência da República. Casa Civil. Constituição da República Federativa do Brasil. Brasília, DF: Senado, 1988.

BRASIL. Presidência da República. Casa Civil. Emenda Constitucional n. 72, de 02 de abril de 2013. Altera a redação do parágrafo único do art. 7ํ da Constituição Federal para estabelecer a igualdade de direitos trabalhistas entre os trabalhadores domésticos e os demais trabalhadores urbanos e rurais. Brasília, DF, 2013.

BRASIL. Presidência da República. Casa Civil. Lei Complementar n. 150, de 1ํ de junho de 2015. Dispõe sobre o contrato de trabalho doméstico; altera as Leis n. 8.212, de 24 de julho de 1991, n. 8.213, de 24 de julho de 1991, e n. 11.196, de 21 de novembro de 2005; revoga o inciso I do art. $3^{\circ}$ da Lei n. 8.009, de 29 de março de 1990, o art. 36 da Lei n. 8.213, de 24 de julho de 1991, a Lei n. 5.859, de 11 de dezembro de 1972, e o inciso VII do art. 12 da Lei n. 9.250, de 26 de dezembro 1995; e dá outras providências. Brasília, DF, 2015.

BRASIL. Presidência da República. Despacho do presidente da República, mensagem n. 289 de oito de julho de 2019. Veta o Projeto de Lei da Câmara n. 11, de 21 de maio de 2016. Diário Oficial da União, Brasília, DF, seção 1, p. 9, coluna 1, 09 jul. 2019.

BRASIL. Senado Federal. Projeto de Lei da Câmara n. 11, de 21 de maio de 2016. Cria e regulamenta as profissões de Cuidador de Pessoa Idosa, Cuidador Infantil, Cuidador de Pessoa com Deficiência e Cuidador de Pessoa com Doença Rara e dá outras providências. Brasília, DF, 2016.

CORSEUIL, Carlos Henrique; FOGUEL, Miguel N. Uma sugestão de deflatores para rendas obtidas a partir de algumas pesquisas domiciliares do IBGE. Brasília: Ipea, 2002. (Texto para Discussão, n. 897). 
COSTA, Joana Simões de Melo; BARBOSA, Ana Luiza Neves de Holanda; HIRATA, Guilherme. Efeitos da ampliação dos direitos trabalhistas sobre a formalização, jornada de trabalho e salários das empregadas domésticas. Rio de Janeiro: Ipea, 2016. (Texto para Discussão, n. 2241).

DEBERT, Guita Grin; OLIVEIRA, Amanda Marques de. A profissionalização da atividade de cuidar de idosos no Brasil. Revista Brasileira de Ciência Política, n. 18, p. 7-41, dez. 2015.

DEVETTER, François-Xavier; JANY-CATRICE, Florence; RIBAULT, Thierry. Les services à la personne. Paris: La Découverte, 2009.

DEVETTER, François-Xavier; ROUSSEAU, Sandrine. Du Balai. Essai sur le ménage à domicile et le retour de la domesticité. Ivry-Sur-Seine: Raisons d’Agir, 2011.

DIEESE - Departamento Intersindical de Estatística e Estudos Socioeconômicos. 0 emprego doméstico no Brasil. São Paulo, 2013. (Estudos e Pesquisas, n. 68).

DUSSUET, Annie. Le genre de l'emploi de proximité. Lien Social et Politiques, n. 47, p. 143-154, 2002.

FRAGA, Alexandre Barbosa. De empregada a diarista: as novas configurações do trabalho doméstico remunerado. Rio de Janeiro: Editora Multifoco, 2013.

GUIMARÃES, Nadya Araujo. Casa e mercado, amor e trabalho, natureza e profissão: controvérsias sobre o processo de mercantilização do trabalho de cuidado. Cadernos Pagu, Campinas, n. 46, p. 59-77, jan.-abr. 2016.

GUIMARÃES, Nadya Araujo; HIRATA, Helena. La frontera entre el empleo doméstico y el trabajo profesional de cuidados en Brasil: pistas y correlatos en el proceso de mercantilización. Sociología del Trabajo, n. 86, p. 7-27, 2016.

GUIMARÃES, Nadya Araujo; HIRATA, Helena Sumiko; SUGITA, Kurumi. Cuidado e cuidadoras: o trabalho do care no Brasil, França e Japão. In: HIRATA, Helena; GUIMARÃES, Nadya Araujo. Cuidado e cuidadoras: as várias faces do trabalho do care. São Paulo: Atlas, 2012. p. 79-102.

IBGE - Instituto Brasileiro de Geografia e Estatística. Estatísticas de gênero: uma análise dos resultados do Censo Demográfico 2010. Rio de Janeiro, 2014.

IBGE - Instituto Brasileiro de Geografia e Estatística. Síntese de indicadores sociais: uma análise das condições de vida da população brasileira. Rio de Janeiro, 2015.

IBGE - Instituto Brasileiro de Geografia e Estatística. Pesquisa Nacional por Amostra de Domicílios. Disponível em: 〈http://www.ibge.gov.br/home〉.

KERSTENETZKY, Celia Lessa; MACHADO, Danielle Carusi. Labor market development in Brazil: formalization, at last? In: AMANN, Edmund; AZZONI, Carlos; BAER, Edmund (ed.). The Oxford handbook of the Brazilian economy. Oxford: Oxford University Press, 2018.

MOURA, Rodrigo Leandro de; BARBOSA FILHO, Fernando de Holanda. A queda da informalidade no Brasil entre 2002 e 2012. In: BONELLI, Regis; VELOSO, Fernando (org.). Panorama do mercado de trabalho no Brasil. Rio de Janeiro: FGV, 2014. p. 125-148.

PAIXÃO, Marcelo; ROSSETTO, Irene. Levantamento das fontes de dados estatísticos sobre a variável cor ou raça no Brasil contemporâneo: terminologias classificatórias, qualidade das bases de dados e implicações para as políticas públicas. In: ENCONTRO ANUAL DA ANPOCS, 35, 2011, Caxambu. Anais [...]. Caxambu: Anpocs, 2011.

PÉRIVIER, Hélène; SILVERA, Rachel. Maudite conciliation. Travail, Genre et Sociétés, v. 24, n. 2, p. 25-27, 2010.

PINHEIRO, Luana et al. Retrato das desigualdades. Brasília: Ipea, SPM, Unifem, 2008. 
SABOIA, João. Baixo crescimento econômico e melhora do mercado de trabalho - como entender a aparente contradição? Estudos Avançados, v. 28, n. 81, p.115-125, maio-ago. 2014.

SORJ, Bila; FONTES, Adriana. O care como regime estratificado: implicações de gênero e classe social. In: HIRATA, Helena; GUIMARÃES, Nadya Araujo. Cuidado e cuidadoras: as várias faces do trabalho do care. São Paulo: Atlas, 2012. p. 103-116.

\section{Sobre as autoras}

Graciele Pereira Guedes é doutoranda do Programa de Pós-graduação em Economia da Universidade Federal Fluminense.

Elisa Alonso Monçores Viana é doutoranda do Programa de Pós-graduação em Economia da Universidade Federal Fluminense. Professora do Departamento de Ciências Econômicas e Exatas do Instituto Três Rios da Universidade Federal Rural do Rio de Janeiro.

\section{Endereço para correspondência}

\section{Graciele Pereira Guedes}

Faculdade de Economia da Universidade Federal Fluminense

Rua Prof. Marcos Valdemar de Freitas Reis, s/n, Bloco F, São Domingos

24210-510 - Niterói-RJ, Brasil

Elisa Monçores

Universidade Federal Rural do Rio de Janeiro - Instituto Três Rios

Av. Prefeito Alberto Lavinas, 1847, Centro

25802-100 - Três Rios-RJ, Brasil

\section{Abstract}

\section{Domestic and professional care workers: sharing the borders of precariousness}

There is considerable fluidity in the border between the professional activity of domestic workers and the assignment performed by care workers. But how different are these occupational categories in relation to their socioeconomic profile? Throughout this article, based on data from the Pesquisa Nacional por Amostra de Domicílios (PNAD), we sought to answer whether during the period 2002-2015 these two groups presented greater approximations or inflections in their characteristics. Based on five analytical dimensions - namely, individual characteristics, working conditions, degree of social and labor protection, household situation, and isolation / belonging - the statistics presented in this paper suggest an approximation over the years between the profile of domestic workers and care professionals. This assertion is valid for practically all indicators analyzed. Both occupations are marked by precariousness at work: they combine low remuneration and social protection levels with many hours of paid work, coupled with long unpaid hours. In addition, they are mostly exercised by black women. Uniquely, schooling is the only socioeconomic characteristic which in fact differentiates the two groups, considerably higher for care workers.

Keywords: Domestic employment. Care. Care workers. Labor market. 


\section{Resumen}

Empleadas domésticas y cuidadoras profesionales: compartiendo las fronteras de la precariedad

Hay una considerable fluidez en la frontera entre la actuación de las empleadas domésticas y las atribuciones ejercidas por las cuidadoras profesionales. Pero ¿cuán distintas son estas categorías de ocupación en lo que refiere a su perfil socioeconómico? Al largo de este artículo, basado en los datos de la Pesquisa Nacional por Amostra de Domicílios (PNAD), buscamos a responder si durante el período 2002-2015 estos dos grupos presentaron mayores aproximaciones o inflexiones en sus características. Desde cinco dimensiones de análisis -características individuales, condiciones de trabajo, grado de protección laboral y social, situación del domicilio y aislamiento/pertenencia - las estadísticas presentadas en este trabajo sugieren una aproximación a lo largo de los años entre el perfil de las trabajadoras domésticas y el de las trabajadoras de cuidados. Esto es válido para prácticamente todos los indicadores investigados. Las dos ocupaciones son marcadas por la precariedad en el trabajo: combinan bajo nivel de remuneración y protección social, a lo que se suman extensas jornadas no remuneradas. Además, son mayoritariamente ejercidas por mujeres negras (pretas) y mestizas (pardas). Específicamente, la escolaridad es la única característica socioeconómica que, de hecho, diferencia a los dos grupos, considerablemente más alta para el grupo de las cuidadoras.

Palabras clave: Empleadas domésticas. Cuidado. Trabajadoras de los cuidados. Mercado de trabajo.

Recebido para publicação em 06/06/2019 Aceito para publicação em 18/09/2019 